\title{
COMPUTATION OF BUCKLING STRENGTH OF REINFORCED CONCRETE COLUMNS BY THE TRANSFER-MATRIX METHOD
}

\author{
H.Taibi Zinai ${ }^{1}$, A. Plumier $^{2}$, D. Kerdal ${ }^{1}$ \\ ${ }^{1}$ Department of Civil Engineering, University of Science and Technology of Oran, Algéria. \\ (Houria_zinai @yahoo.fr) \\ ${ }^{2}$ Department of Civil Engineering, University of Liege, Belgium.
}

\begin{abstract}
The existing methods for predicting of the buckling strength of reinforced concrete are satisfactory for the usual cases of use. However their applicability remains limited. The approximate methods apply only for shorts columns with a small eccentricity of a compression force. The other existing methods impose restrictive conditions: a partially loaded column cannot be modelled by the known methods; concentrated horizontal load or a concentrated moment applied in an unspecified point of the column cannot be treated. The restrictions on the modes of fixing of the supports limit the studies to hinged-hinged columns or to cantilever. The interest of the matrix transfer method for the calculation of the buckling strength of reinforced concrete columns is its flexibility. It allows studying all the external loading cases and all conditions of supports.
\end{abstract}

Keywords: reinforced concrete, structure, buckling, transfer matrix method, column.

\section{INTRODUCTION}

Column buckling is the basic problem in the studies on structural instability. Following the pioneer work by Euler, numerous steps have been made to solve that problem (Buket and Aysun , 2010; Hamid and Mohammad ,2010; Germain, 2006 ; Dinis and Frangopol, 2003). Those work have contributed to the development of various approaches (Kazem and Gowhari , 2008; Mittelstedt, 2007; Kwak and Kim,2004; Kim and Yang, 1995). The most general are those which can be found in finite elements software which take into account material non linearity's and geometrical imperfections. But such analysis is economically justified only for special problems, like important structures or expertise. Approached methods have been elaborated to deal with the most current problems, essentially the design of columns in buildings. All those methods have important limitations (FIB , 1999). Approached methods proposed for reinforced concrete mostly apply to relatively short columns with relatively small eccentricities of the compression force. Other methods apply to slender columns, but they all have restrictive limits of application and several hypotheses at the start of calculations. The general CEB method $(\mathrm{CEB}, 1967)$ only apply to hinged-hinged 
columns; it considers only the first order bending moments and iterations starts with initial rotation and compression strains which are defined a priori; the method does not consider second order effects. I $t$ also does not provide precise calculation of the deformed shape. Other methods, inspired from the general CEB methods also possess restrictive hypothesis of use, though they do not take into account $2^{\text {nd }}$ order effects and suppose a sinusoidal deformed shape. The model column proposes in Eurocode 2 (Eurocode 2, 2004) only apply to cantilever and also has strong limitations of applicability. It also considers that the deformed shape is sinusoidal and deduces $2^{\text {nd }}$ order effects in the limits of that hypothesis. On the contrary, the transfer matrix method which is explained in this paper has not all those limitations mentioned above: no limitations on the support conditions; flexible supports, either translational or rotational can be considered; all cases of external loads; like partial horizontal continuous loading, concentrated forces or a moment applied at any point of the column can be treated; the $2^{\text {nd }}$ moment of area of sections can vary from one element to the next; discontinuities can be introduced between two elements; the real distorted shape can be taken into account in the analysis; second order effects are included in a systematic manner during the successive iterations up to failure. But despite those advantages, the matrix transfer method is little used in civil engineering, though some works can be found (Vrabie, 2010; Starossek, 2009; Saptarshi 1, 2006; Zhi-Yuan and Lan-LanLin 2003). That observation has led to the development of the transfer matrix which is presented in this paper. The writing into algebraic state vectors can reduce the resolution of the problem to a simple linear algebraic problem with three unknowns, which allows a very effective mathematical treatment offering a strong reduction of the required computation capacities.

\section{PUTTING THE PROBLEM IN EQUATIONS}

For a column submitted to a compression force $\mathrm{F}$ with an eccentricity e and with arbitrary modes of support (Figure1).

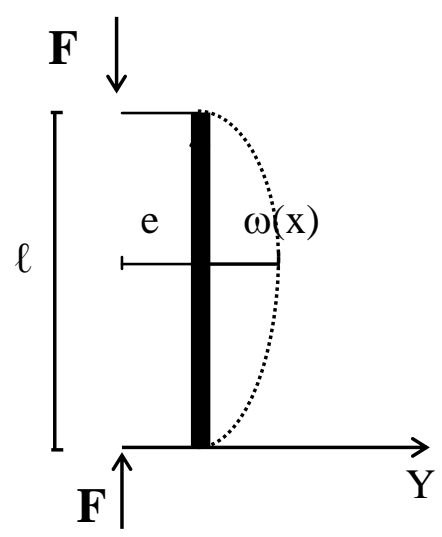

Figure1. Column with eccentric compression 
The basic equation of elasticity which expresses the relation linking the deformation to the bending moment is:

$$
\frac{M}{E I}=\frac{d^{2} \omega}{d x^{2}}
$$

$\mathrm{M}$ is the bending moment at abscises $\mathrm{x}: M(x)=-F \cdot[\omega(x)+e]$

After the replacement of $\mathrm{M}(\mathrm{x})$ in equation (1) and a double derivation, a differential equation of the $4^{\text {th }}$ degree is obtained:

$$
\frac{\mathrm{d}^{4} \omega}{\mathrm{dx}^{4}}+\alpha^{2} \cdot \frac{\mathrm{d}^{2} \omega}{\mathrm{dx}^{2}}=0
$$

With: $\alpha^{2}=(\mathrm{F} / \mathrm{EI}) . \mathrm{F}$ is the eccentric compression force and EI the rigidity in bending.

After solving the differential equation (2), expressions of deformations and stresses are obtained based on initial conditions. (Rouche, 1973). The final deflection is:

$$
\omega(x)=\omega_{0}+\theta_{0} \cdot x+\frac{M_{0}}{E I \alpha^{2}}(1-\cos \alpha x)+\frac{V_{0}}{E I \alpha^{3}}(\sin \alpha x-\alpha x)
$$

The rotation $\theta(\mathrm{x})$, the bending moment $\mathrm{M}(\mathrm{x})$ and the shear force $\mathrm{V}(\mathrm{x})$ are:

$$
\begin{gathered}
\theta(\mathrm{x})=\theta_{0} .+\frac{\sin \alpha \mathrm{x}}{\mathrm{EI} \alpha} \cdot \mathrm{M}_{0}+\left[\frac{\cos \alpha \mathrm{x}-1}{\mathrm{El} \alpha^{2}}\right] \cdot \mathrm{V}_{0} \\
\mathrm{M}(\mathrm{x})=[\cos \alpha \mathrm{x}] \cdot \mathrm{M}_{0}+\left[-\frac{\sin \alpha \mathrm{x}}{\alpha}\right] \cdot \mathrm{V}_{0} \\
\mathrm{~V}(\mathrm{x})=[\alpha \cdot \sin \alpha \mathrm{x}] \mathrm{M}_{0}+[\cos \alpha 0] \cdot \mathrm{V}_{0}
\end{gathered}
$$

with: $\omega_{0}=\omega(0) ; \theta \mathrm{o}=\theta(0) ; \mathrm{Mo}=\mathrm{M}(0) ; \mathrm{Vo}=\mathrm{V}(0)$. 


\section{MATRIX FORMULATION OF DISPLACEMENTS AND INTERNAL FORCES IN A COLUMN UNDER COMPRESSION AND BENDING}

The equations (3) to (6) can be written in matrix form as follows:

$$
\left[\begin{array}{c}
\omega(\mathrm{x}) \\
\theta(\mathrm{x}) \\
\mathrm{M}(\mathrm{x}) \\
\mathrm{V}(\mathrm{x})
\end{array}\right]=\left[\begin{array}{c}
\omega_{0} \\
\theta_{0} \\
\mathrm{M}_{0} \\
\mathrm{~V}_{0}
\end{array}\right] \cdot\left[\begin{array}{cccc}
1 & \mathrm{x} & \frac{1-\cos \alpha \mathrm{x}}{\mathrm{EI} \alpha^{2}} & -\frac{(\alpha \mathrm{x}-\sin \alpha \mathrm{x})}{\mathrm{EI} \alpha^{3}} \\
0 & 1 & \frac{\sin \alpha \mathrm{x}}{\mathrm{EI} \alpha} & -\frac{(1-\cos \alpha)}{\mathrm{EI} \alpha^{2}} \\
0 & 0 & \cos \alpha \mathrm{x} & -\frac{\sin \alpha \mathrm{x}}{\alpha} \\
0 & 0 & \alpha \sin \alpha \mathrm{x} & \cos \alpha \mathrm{x}
\end{array}\right]
$$

\section{DEFINITION OF THE TRANSFER MATRIX OF NODES.}

The principle of the method is to divide the column into several sufficient and adequate portions (Figure 2), (GERY, 1973).

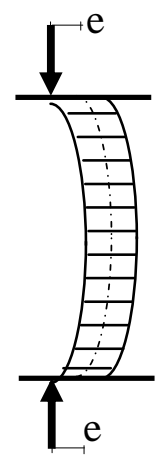

Figure 2. column divide an adequate portions

Each portion EF, (Figure 3), is then defined by its initial vector and its final vector ZF. All discontinuities and different modes of support can be studied through the matrix of nodes. 


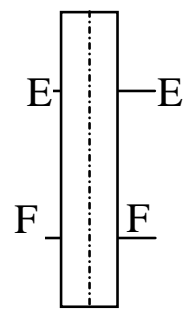

Figure 3. portion EF of the column

The displacement and stress in a section $\mathrm{F}$ can be expressed as functions of displacement and stress of Section E as follows:

$$
\left\{\begin{array}{l}
\omega_{\mathrm{F}}=\mathrm{C}_{11} \cdot \omega_{\mathrm{E}}+\mathrm{C}_{12} \cdot \theta_{\mathrm{E}}+\mathrm{C}_{13} \cdot \mathrm{M}_{\mathrm{E}}+\mathrm{C}_{14} \cdot \mathrm{T}_{\mathrm{E}}+\mathrm{d}_{1} \\
\theta_{\mathrm{F}}=\mathrm{C}_{21} \cdot \omega_{\mathrm{E}}+\mathrm{C}_{22} \cdot \theta_{\mathrm{E}}+\mathrm{C}_{23} \cdot \mathrm{M}_{\mathrm{E}}+\mathrm{C}_{24} \cdot \mathrm{T}_{\mathrm{E}}+\mathrm{d}_{2} \\
\mathrm{M}_{\mathrm{F}}=\mathrm{C}_{31} \cdot \omega_{\mathrm{E}}+\mathrm{C}_{32} \cdot \theta_{\mathrm{E}}+\mathrm{C}_{33} \cdot \mathrm{M}_{\mathrm{E}}+\mathrm{C}_{34} \cdot \mathrm{T}_{\mathrm{E}}+\mathrm{d}_{3} \\
\mathrm{~V}_{\mathrm{F}}=\mathrm{C}_{41} \cdot \omega_{\mathrm{E}}+\mathrm{C}_{42} \cdot \theta_{\mathrm{E}}+\mathrm{C}_{43} \cdot \mathrm{M}_{\mathrm{E}}+\mathrm{C}_{44} \cdot \mathrm{T}_{\mathrm{E}}+\mathrm{d}_{4}
\end{array}\right\}
$$

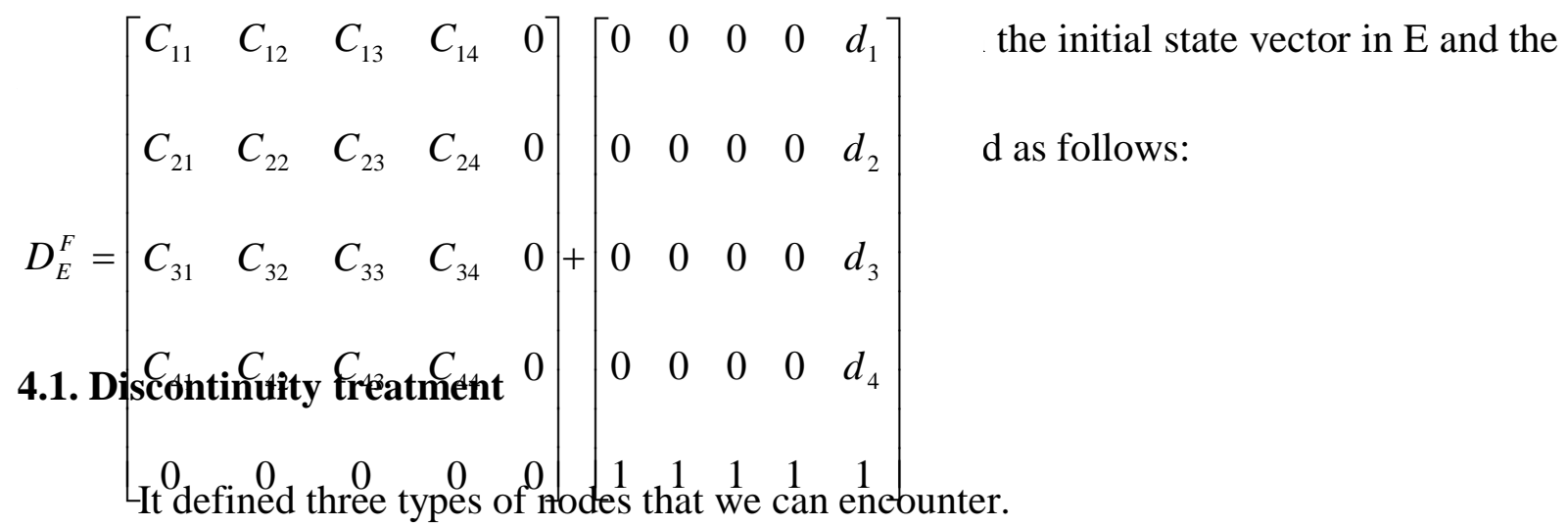

- Fictions nodes : in the cases of variation in cross section and the variation of the distributed load. In this case: $Z_{\mathrm{E}^{\prime}}=\mathrm{Z}_{\mathrm{E}^{\prime \prime}}$

- Nodes fixed elastically: in the case of the elastically support to the bending: $\mathrm{ME}^{\prime \prime}=\mathrm{ME}^{\prime}-K_{E} \cdot \theta_{E}$

Therefore the corresponding transfer matrix is:

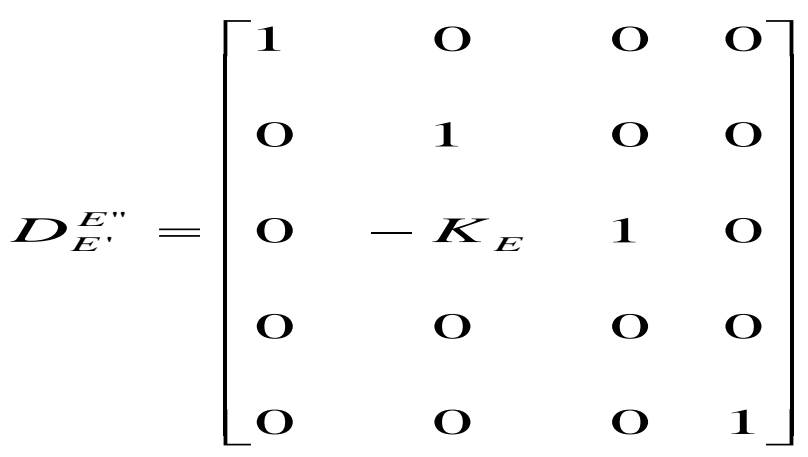

In the case of the elastically support to the deflection: $V_{E^{\prime \prime}}=V_{E^{\prime}}+C_{E} \cdot \omega$ 
Therefore the corresponding transfer matrix is:

$$
D_{E^{\prime}}^{E}=\left[\begin{array}{ccccc}
1 & O & 0 & 0 & 0 \\
O & 1 & 0 & 0 & 0 \\
O & O & 1 & 0 & 0 \\
C_{E} & O & O & 1 & 0 \\
O & O & O & O & 1
\end{array}\right]
$$

- Loaded nodes: in the case of the increase of the deflection: $\omega_{\mathrm{E}^{\prime \prime}}=\omega_{\mathrm{E}^{\prime}}+\Delta_{\omega \mathrm{E}}$ Therefore the corresponding transfer matrix is:

$$
D_{E^{*}}^{E^{\prime \prime}}=\left[\begin{array}{ccccc}
1 & 0 & 0 & 0 & \Delta_{\omega E} \\
O & 1 & O & 0 & 0 \\
O & O & 1 & O & O \\
O & O & O & 1 & O \\
O & O & O & O & 1
\end{array}\right]
$$

In the case of the increase of the flexional rotation: $\theta_{E^{\prime \prime}}=\theta_{E^{\prime}}+\Delta \theta_{E}$ Therefore the correspondent transfer matrix is:

$$
D_{E^{\prime}}^{E^{\prime \prime}}=\left[\begin{array}{ccccc}
1 & 0 & 0 & 0 & 0 \\
0 & 1 & 0 & 0 & \Delta \theta \\
0 & 0 & 1 & 0 & 0 \\
0 & 0 & 0 & 1 & 0 \\
0 & 0 & 0 & 0 & 1
\end{array}\right]
$$

In the case of the concentrated flexural moment: $M_{E^{\prime \prime}}=M_{E^{\prime}}+M_{E}$ Therefore the correspondent transfer matrix is: 


$$
D_{E^{\prime}}^{E^{\prime \prime}}=\left[\begin{array}{ccccc}
1 & 0 & 0 & 0 & 0 \\
0 & 1 & 0 & 0 & 0 \\
O & 0 & 1 & 0 & M_{E} \\
O & 0 & 0 & 1 & 0 \\
0 & 0 & 0 & 0 & 1
\end{array}\right]
$$

In the case of the concentrated load: $T_{E^{n}}=T_{E^{\prime}}-P_{E}$

Therefore the correspondent transfer matrix is:

$$
D_{E^{\prime}}^{E^{\prime \prime}}=\left[\begin{array}{ccccc}
1 & 0 & 0 & 0 & 0 \\
0 & 1 & 0 & 0 & 0 \\
0 & 0 & 1 & 0 & 0 \\
0 & 0 & 0 & 1 & -P_{E} \\
0 & 0 & 0 & 0 & 1
\end{array}\right]
$$

\section{ALGEBRAIC WRITING OF THE STATE VECTOR}

The difficulty in the study by the transfer matrix is the definition of the junction between the different sections, the definitions of state vectors at both ends of the column, and the transition from one section to another. The algebraic writing of the state vectors of the segment can solve all these problems (Rakovsky, 1985).

The state vector of the initial support of the column can be given for different types of fixation. For the first section " $\mathrm{G}_{0}$ " of the column, and depending on the support, the state vector is defined below for each case.

For a free extremity:

$$
\mathrm{Z}_{\mathrm{G}_{0}}=\left[\begin{array}{c}
\omega_{0} \\
\theta_{0} \\
0 \\
0 \\
1
\end{array}\right]
$$


For a simple support:

$\mathrm{Z}_{\mathrm{G}_{0}}=\left[\begin{array}{c}0 \\ \theta \\ 0 \\ \mathrm{~T}_{0} \\ 1\end{array}\right]$

For a perfect embedding:

$\mathrm{Z}_{\mathrm{G}_{0}}=\left[\begin{array}{c}0 \\ 0 \\ \mathrm{M}_{0} \\ \mathrm{~T}_{0} \\ 1\end{array}\right]$

It is noticeable that in each case, two components are nil and two components are non nil. If A, B are the nonzero components, a linear combination can be written from A to B.

$$
\mathrm{A}=d \cdot \mathrm{B}+\mathrm{f}
$$

The linear relation (7) can be applied to all cases to support the initial section. Thus, for a free end, the relationship is: 


$$
\mathrm{Z}_{\mathrm{G}_{0}}=\left[\begin{array}{c}
\omega_{0} \\
\theta_{0} \\
0 \\
0 \\
0 \\
0 \\
1
\end{array}\right]=\left[\begin{array}{c}
A \\
0 \\
0 \\
1
\end{array}\right]=\left\{\left[\begin{array}{c}
d . B+f \\
0 \\
0 \\
0 \\
0 \\
0 \\
0
\end{array}\right] \cdot d+\left[\begin{array}{l}
1 \\
1 \\
0 \\
0 \\
0 \\
0 \\
0 \\
0 \\
0 \\
0 \\
0 \\
0 \\
0 \\
0 \\
0 \\
0 \\
0
\end{array}\right]\right\}
$$

The relation (8) can be written

$$
\mathrm{ZG}_{0}=\left[\left(\mathrm{d} \cdot \mathrm{WG}_{01}+\mathrm{WG}_{02}\right) \cdot \mathrm{B}+\left(\mathrm{WG}_{01} \cdot \mathrm{f}+\mathrm{WG}_{03}\right)\right]
$$

So, for all cases of supports, only the vectors $\mathrm{WG}_{01}, \mathrm{WG}_{02}$ change. (Rakovsky, 1985). For the general case, $\mathrm{ZG}_{0}$ defines the support of the initial section of the column. The state vector of the last section of the first segment can be defined in function of the matrix $D_{0}^{1}$, as:

$$
\begin{gathered}
Z_{D_{1}}=D_{0}^{1} \cdot Z_{G_{0}}=\mathrm{D}_{0}^{1}[(\mathrm{~d} \cdot \mathrm{WG} 1+\mathrm{WG} 2) \cdot \mathrm{B}+(\mathrm{f} \cdot \mathrm{WG} 1+\mathrm{WG})] \\
=[(\mathrm{d} \cdot \mathrm{WD} 1+\mathrm{WD} 2) \cdot \mathrm{B}+(\mathrm{f} \cdot \mathrm{WD} 1+\mathrm{WD} 3)]
\end{gathered}
$$

It is deduced that: WDi $=\mathrm{D}_{0}^{1}$.WGi

Finally, it follows that: $Z D_{1}=X_{1} \cdot B+R$, and, $Z D_{1, k}=X_{k} \cdot B+R_{k}$

\section{CALCULATION OF THE BUCKLING STRENGTH.}

After determining the stresses and displacements of the column, it remains to verify its stability. The column stability is ensured when there is a balance between (solicitationsdisplacements) and (internal efforts - deformations) in the most critical section. When the equilibrium is not possible, it is deduced that failure is reached.Failure occurs either by instability when the column is long, or by loss of resistance when the column is short. The internal forces and constraints for the critical section of the column are determined using the actual rotation of the column and not imposed ones as in the existing calculation methods. Indeed, the rotation for the cross section considered is deduced from equation (4). The relationship between the rotation and the deformation diagrams is: $\theta=\frac{\varepsilon c}{X}$

The neutral axis $\mathrm{X}$ is related to the deformation diagram by the relationship: $X=\frac{\varepsilon c}{\varepsilon s+\varepsilon c} \cdot d$ 
Knowing the position of the neutral axis $\mathrm{X}$, the deformation diagrams and the stress diagram of concrete and steel, it is possible to calculate the compressive force $\mathrm{N}_{\mathrm{Rd}}$ and the resistance moment $M_{R d}$ :

$$
\begin{gathered}
\mathrm{N}_{\mathrm{Rd}}=\mathrm{N}_{\mathrm{Rc}}+\mathrm{N}_{\mathrm{sc}}-\mathrm{N}_{\mathrm{s}} \\
M_{R d}=N_{R c} \cdot X 1+N_{s c} \cdot X 2-N_{s} \cdot X 3
\end{gathered}
$$

The internal eccentricity then is:

$$
\mathrm{e}_{\mathrm{i}}=\frac{\mathrm{M}_{\mathrm{Rd}}}{\mathrm{N}_{\mathrm{Rd}}}
$$

In order to obtain the stability, it must be verified at the same time that: $\left\{\begin{array}{l}F \leq N_{R d} \\ \omega \leq e_{i}\end{array}\right.$

The whole of the method presented above has been expressed into a software named "FLAMBE" (for "column buckling" in French). It allows compute the buckling load of columns of very different shapes and support conditions. But it is necessary, in order to eliminate possible errors in the writing of the equations of the problem, to validate that tool by means of a confrontation between test results and computation results.

\section{CONFRONTATION BETWEEN COMPUTATION AND EXPERIMENTAL RESULTS}

The modeling has concerned columns that have been tested in laboratories and whose characteristics and behavior have been published (FOURE,1975). Among the tests modeled which were modeled in this study, thirty are presented in this paper. They correspond to a set of columns with various geometrical dimensions and various material characteristics (FOURE, 1978). However tests on columns with other modes of support than hinged-hinged or with other loading mode than compression only are lacking, so that the confrontation still has a limited character.

\subsection{Description of the studied}

For all models studied, the compression force-deflection curves are presented with indication of the value of the compression force at failure (figures 4 to 10). Tables provide the experimental and the computed values of failure loads, the ratio between those values, the average, the standard deviation and the coefficient of variation of every sample.

\subsection{The studied tests}


A research of all existing buckling test results of reinforced concrete columns has been made (CEB, 1967). That research has led to keep as well documented the following tests, on which computation have been made using the transfer matrix method:

- tests of F.G. THOMAS on twelve columns with square section 15,24x 15,24 cm, hinged at their ends (Table1);

- tests of O. BAUMANN. Among the twenty studied tests of BAUMANN, six are presented; they concern the specimens with meaningful parametric differences, (Table 4);

- tests of ROBINSON, FOURE and SAMEBDJEM on three hinged-hinged columns I1, II1, III1, of transverse section $15 \times 20 \mathrm{~cm}$ and five hinged-hinged columns, DB1, DB2, DB3, DF1, DF2, of transverse section of $15 \times 30 \mathrm{~cm}$ ( Table 6);

- tests of STEKELENBURG. Four tests on hinged-hinged columns with transverse section is $15 \times 15 \mathrm{~cm}$ (Table 8). have been studied.

Figure 4. Curves (Deflexion- Normal efforts) for THOMAS' column

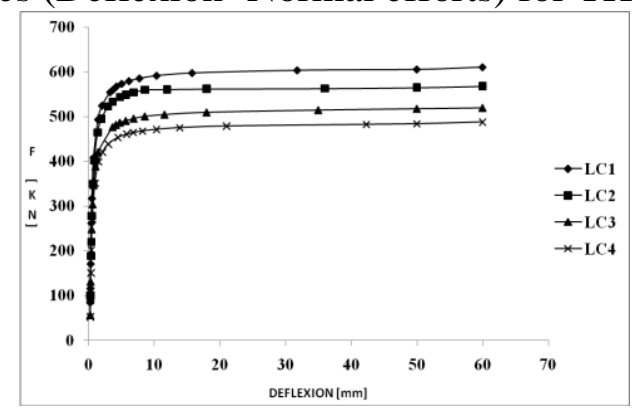

Figure 5. Curves (Deflexion- Normal efforts) for THOMAS' column

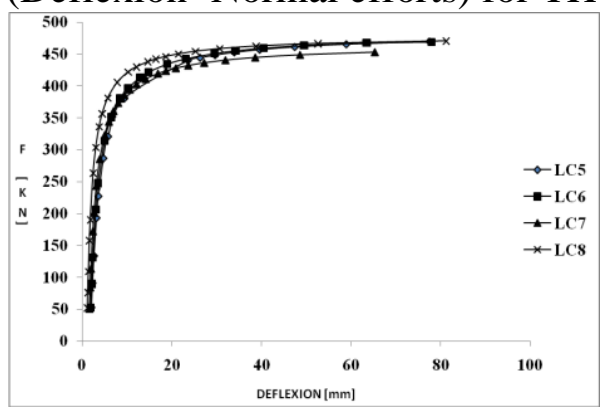

Figure 6. Curves (Deflexion- Normal efforts) for THOMAS' columns

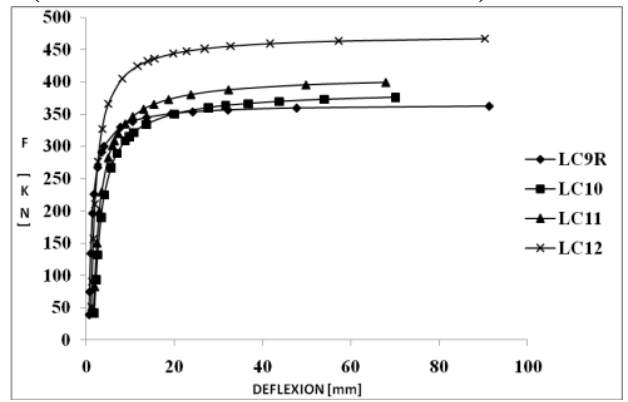


Figure 7. Curves (Deflection- Normal efforts) for BAUMANN ' column

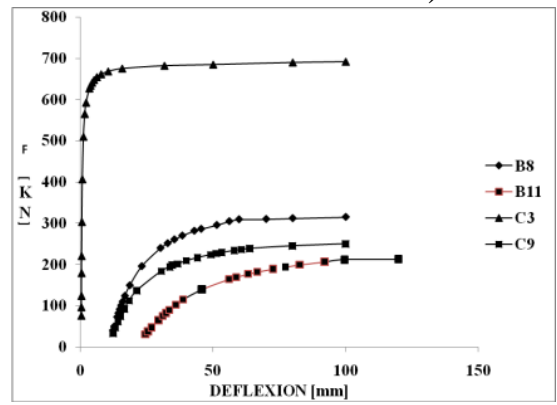

Figure 8. Curves (Deflection- Normal efforts) for the columns of ROBINSON, FOURE

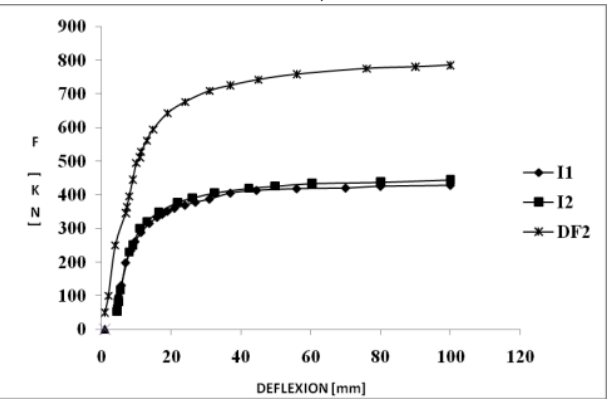

Figure 9. Curves (Deflection- Normal efforts) for the columns of ROBINSON, FOURE

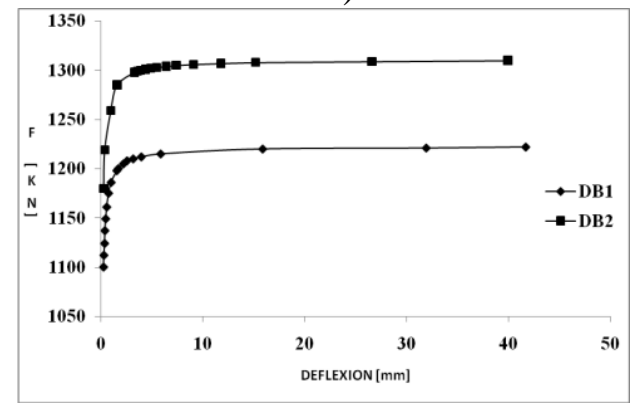

Figure 10. Curves (deflection - normal efforts) for the columns of SIEVE STEKELENBURG

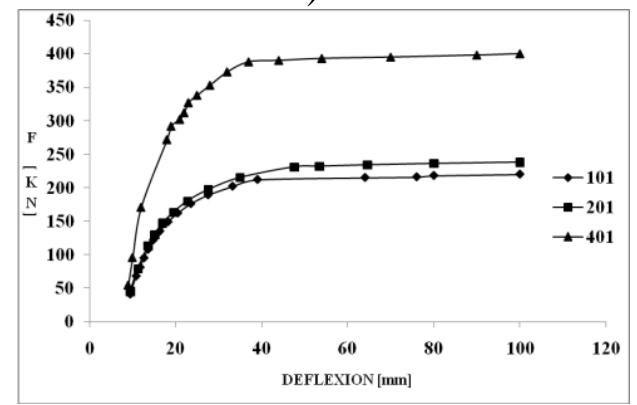




\subsection{Discussion of the results}

The validity of the transfer matrix method which has been developed can be assessed by looking at the values of the ratios between the experimental ultimate loads and the computed ultimate loads, as well as by the standard deviation and the coefficient of variation for each sample of test specimens; those values are presented at Tables (1 to4).

- The columns of F.G.THOMAS (table 1)

All columns have a percentage of steel equal to $2.18 \%$. For all these columns the difference between the experimental ultimate loads and ultimate loads calculated by this method is low. This is confirmed by the average ratio of experimental ultimate loads and ultimate loads calculated which is 1.01 and the coefficient of variation, which is equal at $3.7 \%$. This leads to the conclusion that the dispersion of results is low and the method of calculation is valid for these columns.

Table 1. Calculated values of the critical loads for THOMAS' columns

\begin{tabular}{|c|c|c|c|c|}
\hline TEST & $\mathrm{N} \exp$ & Ncal & $\mathrm{N} \exp / \mathrm{Ncal}$ & \\
\hline LC1 & 588,4 & 593 & 0,99 & \\
\hline $\mathrm{LC} 2$ & 544,2 & 561 & 0,97 & \\
\hline LC3 & 478,9 & 503 & 0,95 & \\
\hline LC4 & 465,43 & 470 & 0,99 & \\
\hline LC5 & 455,8 & 445 & 1,02 & \\
\hline LC6 & 448,1 & 450 & 0,99 & \\
\hline LC7 & 463,6 & 442 & 1,05 & \\
\hline LC8 & 474,7 & 456 & 1,04 & \\
\hline LC9R & 359,8 & 350 & 1,03 & \\
\hline LC10 & 373,7 & 365 & 1,02 & \\
\hline LC11 & 418,5 & 385 & 1,09 & \\
\hline LC12 & 438,4 & 450 & 0,97 & \\
\hline \multicolumn{4}{|c|}{$\begin{array}{l}\text { The middle value of the report } \\
\mathrm{N}_{\exp } / \mathrm{N}_{\mathrm{cal}}\end{array}$} & 1,01 \\
\hline \multicolumn{4}{|c|}{ Coefficient of variation } & 0,037 \\
\hline
\end{tabular}

- The columns of O. BAUMANN (table 2)

The columns B8, B11 and B11 are the long columns with a slenderness equal to 89. The columns C3, C6 and C9 are the very long columns with a slenderness equal to 141. They have respectively the same percentage of steel, with change of other parameters. For all these columns the difference between the experimental ultimate loads and ultimate loads calculated by this method is low. This is confirmed by the average ratio of experimental ultimate loads and ultimate loads calculated which is 0,94 and the coefficient of variation, which is equal at 0,11 . This leads to the conclusion that the dispersion of results is low and the method of calculation is valid for these columns. 
Table 2. Calculated values of the critical loads for the columns of BAUMANN

\begin{tabular}{|c|c|c|c|c|}
\hline TESTS & $\mathrm{N}_{\exp }$ & Ncal & $\mathrm{N}_{\text {exp } / \mathrm{Ncal}}$ & \\
\hline B8 & 233,822 & 280 & 0,83 & \\
\hline B11 & 193,159 & 201 & 0,96 & \\
\hline B14 & 233,822 & 205 & 0,80 & \\
\hline $\mathrm{C} 3$ & 666,04 & 680 & 0,98 & \\
\hline C6 & 225,637 & 202 & 1,12 & \\
\hline C9 & 203,449 & 221 & 0,92 & \\
\hline \multicolumn{4}{|c|}{$\begin{array}{l}\text { The middle value of the report } \\
N_{\exp } / N_{c a l}\end{array}$} & 0,94 \\
\hline \multicolumn{4}{|c|}{ Coefficient of variation } & 0,11 \\
\hline
\end{tabular}

-The columns of ROBINSON, FOURE, SAMEBDJEM (table 3)

These columns are the very long columns with slenderness equal to 141 , with change of more parameters. For all these columns the difference between the experimental ultimate loads and ultimate loads calculated by this method is low. This is confirmed by the average ratio of experimental ultimate loads and ultimate loads calculated which is 0,963 and the coefficient of variation, which is equal at 0,09 . This leads to the conclusion that the dispersion of results is low and the method of calculation is valid for these columns.

Table 3. Calculated Values of the critical loads for the columns of ROBINSON,

FOURE and SAMEBDJEM

\begin{tabular}{|c|c|c|c|c|}
\hline TESTS & $\mathrm{N}_{\exp }$ & Ncal & $\mathrm{N}_{\exp / \mathrm{Ncal}}$ & \\
\hline I1 & 387 & 397 & 0,98 & \\
\hline II1 & 444 & 427 & 1,04 & \\
\hline III1 & 427 & 391 & 1,09 & \\
\hline DB1 & 1079 & 1210 & 0,892 & \\
\hline DB2 & 1030 & 1300 & 0,79 & \\
\hline DB3 & 1055 & 1325 & 0,99 & \\
\hline DF1 & 1226 & 1290 & 0,95 & \\
\hline DF2 & 736 & 758 & 0,97 & \\
\hline \multicolumn{4}{|c|}{$\begin{array}{l}\text { The middle value of the report } \\
\mathrm{N}_{\text {exp }} / \mathrm{N}_{\text {cal }}\end{array}$} & 0,963 \\
\hline \multicolumn{4}{|c|}{ Coefficient of variation } & 0,09 \\
\hline
\end{tabular}

-The columns de VAN STEKELENBURG (table 4)

The columns 101,201 and 301 are the long columns with slenderness equal to 89 . They have the same initial eccentricity of the normal force equal to $20 \%$ of the height of the section of the column. The column 401 is a post which the slenderness ratio equal to 54 and whose initial eccentricity of the normal force equal to $20 \%$ of the height of the section of the column.

For these four columns the difference between the experimental ultimate loads and ultimate loads calculated by this method is low. This is confirmed by the average ratio of expe- 
rimental ultimate loads and ultimate loads calculated which is 0,9 and the coefficient of variation, which is equal at 0,06 . This leads to the conclusion that the dispersion of results is low and the method of calculation is valid for these columns.

Table 4. Calculated Values of the critical loads for the columns of STEKELENBURG

\begin{tabular}{|c|c|c|c|c|}
\hline TESTS & $\mathrm{N}_{\exp }$ & Ncal & $\mathrm{N}_{\text {exp } / \text { Ncal }}$ & \\
\hline 101 & 179,5 & 205 & 0,875 & \\
\hline 201 & 229,6 & 232 & 0,99 & \\
\hline 301 & 310,1 & 370 & 0,838 & \\
\hline 401 & 345 & 385 & 0,896 & \\
\hline \multicolumn{4}{|c|}{$\begin{array}{l}\text { The middle value of the report } \\
\qquad \mathrm{N}_{\exp } / \mathrm{N}_{\mathrm{cal}}\end{array}$} & 0,90 \\
\hline \multicolumn{4}{|c|}{ Coefficient of variation } & 0,06 \\
\hline
\end{tabular}

Finally, we note that the values of the ratios between experimental ultimate load and ultimate load calculated are between 0.90 and 1.01. The coefficients of variation are below 11\%.(table 5).

We therefore conclude that the dispersion of results is small and the calculation method is accurate for the cases studied

Table 5. Calculated values for the studied tests

\begin{tabular}{|c|c|c|c|c|}
\hline Authors & $\begin{array}{l}\text { Number } \\
\text { of tests }\end{array}$ & $\begin{array}{l}\text { Average } \\
\text { ratio }\end{array}$ & $\begin{array}{l}\text { gap } \\
\text { marks }\end{array}$ & $\begin{array}{l}\text { Coefficient of } \\
\text { variation }\end{array}$ \\
\hline THOMAS & 12 & 1,01 & $3,7 \%$ & 0,037 \\
\hline BAUMANN & 6 & 0,94 & $10,5 \%$ & 0,11 \\
\hline $\begin{array}{l}\text { ROBINSON,FOUR, } \\
\text { SAMEBDJEM, }\end{array}$ & 8 & 0,96 & $8,6 \%$ & 0,09 \\
\hline STEKELENBURG & 4 & 0,90 & $5,61 \%$ & 0,06 \\
\hline
\end{tabular}

\section{CONCLUSION}

The comparison between test buckling loads and failure loads computed with the transfer matrix method set forward the fact that the computation method gives a good accuracy in the estimation of buckling strength of reinforced concrete columns. The method, which is light and flexible in numerical computations, has not the limitations which characterize other existing methods. It will thus be usefull to solve problems in situations which are more complex than the simple hingedhinged column; in particular, all the situations with complex supports, variable sections dimensions or with loads applied in the span of the column, can be successfully studied by the method. 


\section{REFERENCES}

[1] Buket, O. B. and Aysun B., "Buckling Characteristics of Symmetrically and Ant symmetrically Laminated Composite Plates with Central Cutout", Chemistry and Materials Science, Applied Composite Materials, Vol. 14, 265-276, 2010.

[2] CEB, Comité européen du béton, Bulletin d'information Nº62, flambement, Septembre 1967.

[3] Christian Mittelstedt, "Local buckling of wide-flange thin-walled anisotropic composite beams", Archive of Applied Mechanics, Vol. 77, 439-452, 2007.

[4] Dinis, S., and Frangopol D. "Safety evaluation of slender high-strength concrete columns under sustained loads” . Computer and structures,81, 1475-1486, 2003.

[5] ENV 1992-1-1: EUROCODE 2: "Calcul des structures en béton : Règles générales et règles pour les bâtiments", 2004.

[6] Espion, B., "Aspects approfondis du calcul des constructions en béton”, Cours universitaire, université libre de Bruxelles, 2001.

[7] FIB 1999, Fédération Internationale du béton, Structural concrete, Textbook on behaviour, design and performance, Update knowledge of CEB-FIP MODEL 1990, Vol. 1, 1999.

[8] Fouré, B., "Le flambement des poteaux en béton armé avec des excentricités différentes ", Annales ITBTP vol. 8, n 333, 1978.

[9] Fouré, B., "Le flambement des poteaux compte tenu du fluage du béton", Annales ITBTP, vol. $8, \mathrm{n}^{\circ} 359,1975$.

[10] Germain, O. "Contribution à l'analyse du comportement et au dimensionnement des colonnes élancées en béton armé”, Thèse de doctorat, Université libre de Bruxelles, 2006.

[11] Hamid, RO. , Sayyed, A.M. G. and Mohammad H. S., "Buckling Analysis of Laminated Composite Plates Using Higher Order Semi Analytical Finite Strip Method",Applied Composite Materials, Vol. 17, 69-80,2010.

[12] Gery, P M., "Les matrices transfert dans le calcul des structures”, Paris, Eyrolles, 1973.

[13] Kazem Y. and Gowhari A. R.," Carrying capacity of edge-cracked columns under concentric vertical loads", Acta Mechanica, Vol. 198, 1-19, 2008.

[14] Kim, JK. and Yang, JK., "Buckling behaviour of slender high-stregth concrete column", Engineering structures, Vol.17, 39-51, 1995.

[15] Kwak, HG. and Kim, JK., "Ultimate resisting capacity of slender RC columns", Computers and structures, $82,901-9015,2004$. 
[16] Rakovsky G. ,"Kamputerawa mechanikoKonstrukti”, Notes de cours de SHUBERT, département de mécanique, Université des sciences et de la technologie d'Oran, Algérie, 1985.

[17] Rouche, M., "Equations différentielles ordinaires”, Paris, Masson, 1973.

[18] Starossek, U., Löhning, T. and Schenk, J., "Nonlinear Analysis of Reinforced Concrete Frames by a Combined Method", Electronic Journal of Structural Engineering, 9, 2009.

[19] Saptarshi, S. and Ramanjaneyulu,K., "Transfer matrix method for construction phase analysis of incrementally launched prestressed concrete bridges", Engineering Structures, 28, 2006.

[20] Taibi, H. and Plumier, A., "Study of the columns buckling in reinforced concrete trough the transfer matrix method”, ICCES1, Assiout, Egypte, Proceeding, 416-427. 2003.

[21] Vrabie, M., Ungureanu, N.and Diaconu-Sotropa, D., "Transfer matrix method for orthotropic cylindrical shells with variable thickness", Proceedings of the Romanian Academy, Vol. 11, 2010.

[22] ZhiYuan, L. and LanLan, L., "Photonic band structures solved by a plane-wave-based transfer-matrix method”, Physical Review 67, 0466072003. 